OPEN ACCESS

Edited by:

Cesare Indiveri,

University of Calabria, Italy

Reviewed by:

Valeria Rachela Villella

European Institute for Research in

Cystic Fibrosis (IERFC), Italy

Paul Hruz,

Washington University in St. Louis,

United States

*Correspondence:

Lida Wu

wldpaper@pku.edu.cn;

wldpaper@gmail.com

Yuchun Gu

ycgu@pku.edu.cn

${ }^{\dagger}$ These authors have contributed equally to this work and share first

authorship

Specialty section:

This article was submitted to

Cellular Biochemistry,

a section of the journal

Frontiers in Cell and Developmental

Biology

Received: 19 November 2020

Accepted: 27 January 2021

Published: 15 February 2021

Citation:

Gu J, Zhang W, Wu L and Gu Y

(2021) CFTR Deficiency Affects

Glucose Homeostasis via Regulating

GLUT4 Plasma Membrane

Transportation

Front. Cell Dev. Biol. 9:630654.

doi: 10.3389/fcell.2021.630654

\section{CFTR Deficiency Affects Glucose Homeostasis via Regulating GLUT4 Plasma Membrane Transportation}

\author{
Junzhong $\mathrm{Gu}^{1+}$, Weiwei Zhang ${ }^{2 \dagger}$, Lida $\mathrm{Wu}^{1 *}$ and Yuchun $\mathrm{Gu}^{1,3 *}$ \\ ${ }^{1}$ Molecular Pharmacology Laboratory, Institute of Molecular Medicine, Peking University, Beijing, China, ${ }^{2}$ Peking-Tsinghua \\ Center for Life Sciences, Peking University, Beijing, China, ${ }^{3}$ Translational and Regenerative Medicine Centre, Aston Medical \\ School, Aston University, Birmingham, United Kingdom
}

Cystic Fibrosis (CF) is an autosomal recessive disorder caused by mutations in the Cystic Fibrosis Transmembrane Conductance Regulator (CFTR) gene. CF-related diabetes (CFRD) is one of the most prevalent comorbidities of CF. Altered glucose homeostasis has been reported in CF patients. The mechanism has not been fully elucidated. Besides the consequence of pancreatic endocrine dysfunction, we focus on insulinresponsive tissues and glucose transportation to explain glucose homeostasis alteration in CFRD. Herein, we found that CFTR knockout mice exhibited insulin resistance and glucose tolerance. Furthermore, we demonstrated insulin-induced glucose transporter 4 (GLUT4) translocation to the cell membrane was abnormal in the CFTR knockout mice muscle fibers, suggesting that defective intracellular GLUT4 transportation may be the cause of impaired insulin responses and glucose homeostasis. We further demonstrated that $\mathrm{PI}(4,5) \mathrm{P}_{2}$ could rescue CFTR related defective intracellular GLUT4 transportation, and CFTR could regulate $\mathrm{PI}(4,5) \mathrm{P}_{2}$ cellular level through PIP5KA, suggesting $\mathrm{PI}(4,5) \mathrm{P}_{2}$ is a down-stream signal of CFTR. Our results revealed a new signal mechanism of CFTR in GLUT4 translocation regulation, which helps explain glucose homeostasis alteration in CF patients.

Keywords: cystic fibrosis, CFTR, CF-related diabetes, glucose homeostasis disorder, GLUT4

\section{INTRODUCTION}

Cystic fibrosis (CF) is one of the most common autosomal recessive disorders in the Caucasian population. It is caused by mutations in the CFTR gene. CF-related diabetes (CFRD) affects 19\% of adolescents with CF (Moran et al., 2010), 50\% adults CF patients (Moran et al., 2009, 2010), indicating that CFRD is a progressive complication of CF. Despite advances in therapies designed to address the disease's symptoms, the death rate is still high. As a result, it is crucial to study the mechanism of CFRD thoroughly.

One of the prevailing mechanistic beliefs is that CFRD results from defective insulin secretion of pancreatic $\beta$-cell, which is due to the combination of chronic pancreatitis and eventual loss of the islet cells (Cucinotta et al., 1994; Marshall et al., 2005; Costa et al., 2007; Mohan et al., 2009; Guo et al., 2014). Autopsy data confirmed the eventual loss of islet tissue and decreased $\beta$-cell

Abbreviations: CF, Cystic Fibrosis; CFTR, Cystic Fibrosis Transmembrane Conductance Regulator; CFRD, Cystic Fibrosis related diabetes; GLUT4, Glucose Transporter 4. 
numbers in aged CF patients (Iannucci et al., 1984; Lohr et al., 1989). However, most CF patients demonstrate abnormalities in glycaemic control regardless of the class and severity of the CFTR mutation (Wooldridge et al., 2015). Of the thousand CFTR mutations that have been identified, approximately 20 are understood to be disease-causing and are categorized into five classes of mutations of increasing disease severity (Manderson Koivula et al., 2017). CFTR in the regulation of insulin secretion and $\beta$ cell function has also been reported as the mechanism of CFRD by several recent studies (Stalvey et al., 2006; Edlund et al., 2014; Guo et al., 2014; Fontes et al., 2015), which cannot fully explain the impaired insulin responses and glucose homeostasis reported in CF patients. In addition to the traditional view that CFRD is the consequence of pancreatic endocrine dysfunction, we speculated that CFRD might also affect insulin-responsive tissues' function.

Several studies found that CF patients with overt diabetes exhibited peripheral and hepatic insulin resistance (Moran et al., 1994; Holl et al., 1995; Hardin et al., 2001; Fontes et al., 2015; Boudreau et al., 2016). However, little is known regarding the mechanism of CFTR loss-of-function in insulin resistance. Insulin facilitates the entry of glucose into muscle, adipose, and several other tissues. The typical mechanism by which cells can take up glucose is by facilitated diffusion through a family of hexose transporters. Skeletal muscle provides the most substantial contribution $(\sim 70 \%)$ of insulin-dependent glucose disposal, and this process is mediated by the insulin-responsive glucose transporter 4(GLUT4) (Bouche et al., 2004; Leto and Saltiel, 2012). As a result, we speculated that CFTR deficiency might result in impaired insulin action and GLUT4 dysfunction in skeletal muscle. In this study, we found that CFTR knockout mice exhibited altered glucose homeostasis, and the reason was defective intracellular GLUT4 transportation.

\section{MATERIALS AND METHODS}

\section{Cell Culture and Transfection}

Flexor Digitorum Brevis (FDB) muscle fibers isolation from mice skeletal muscle was previously described (Park et al., 2014). Mouse skeletal muscle cell lines, C2C12 myoblasts, were cultured in DMEM (GIBCO \#11965) supplemented with 10\% FBS (HyClone \#30071.03). C2C12 myotubes differentiation was then induced by switching the medium to DMEM supplemented with 2\% HS (GIBCO \#26050070). The medium was changed every $24 \mathrm{~h}$. The plasmid of myc-GLUT4-EGFP, bearing the c-Myc epitope tag in the first extracellular loop and GFP at the carboxyl terminus, was purchased from addgene (\#52872). According to the manufacturer's instructions, the plasmid was transfected into HEPG2 and Hela cells using Lipofectamine 2000 (Invitrogen). C2C12 myoblasts and myotubes were transfected with adenovirus (Vigenebio, China) to express myc-GLUT4EGFP protein.

\section{Immunofluorescent Analysis}

Cells that express myc-GLUT4-EGFP were cultured with media supplemented with 1\% FBS overnight and then were treated with insulin $(100 \mathrm{nM})$ for $30 \mathrm{~min}$. Cells were then fixed with $4 \%$ paraformaldehyde, followed by immunocytochemistry using the anti-Myc antibody (Beijing TDY Biotech LTD, \#TDY002) and Cy3 -conjugated anti-mouse IgG antibody (Beijing CWBIO, \# CW0145S). The cells were imaged with a spin disk confocal system (Revolution XD; ColdSpring Science Corporation) with a CSU-X1 confocal head (Yokogawa) mounted on an inverted microscope (IX81ZDC2; Nikon) with Perfect Focus, using an EMCCD camera (iXon3 DU-897D-C00\#BV; Andor). MetaMorph controlled image acquisition and all other peripherals.

\section{Animal Experiments}

All methods were carried out following relevant guidelines and regulations. All experimental protocols were approved by the University Ethics Committee, Institute of Molecular Medicine, Peking University. All animals received humane care in compliance Guide for the Institutional Animal Care and Use Committee (IACUC). CFTR knockout (KO) and heterozygote (HET) mice were purchased from Jackson Lab(CFTR S489X-) and bred to generate homozygous mutants $(\mathrm{KO})$, heterozygote (HET), and wild-type (WT) mice. CFTR KO mice were genotyped by standard PCR according to the genotyping protocol. Mice were housed under controlled temperature $\left(21^{\circ} \mathrm{C}\right)$ on a $12 \mathrm{~h}$ light-dark cycle with unrestricted access to food and water.

FABP-hCFTR-CFTR transgenic mice harbor the FABPhCFTR transgene and a targeted knock-out mutation of the CFTR. This model may be used to assess the effects of the null mutation and may be useful as a mouse model of severe phenotype cystic fibrosis.

\section{Glucose Tolerance Test, Insulin Tolerance Tests, and Determination of Insulin Levels in vivo}

For glucose tolerance tests (GTTs), the mice were starved overnight and were given $2.5 \mathrm{~g} / \mathrm{kg}$ body weight of glucose by IP injection. Blood was then taken from the tail vein before and 15, 30, 60, and $120 \mathrm{~min}$ after injection to determine blood glucose by using an Accu-Chek blood glucose monitor (Roche). To determine insulin plasma levels, blood was collected, and the plasma was obtained, and analysis was performed with an insulin ELISA (Millipore). For ITT, $5 \mathrm{~h}$ fasted mice were given human insulin $(0.75 \mathrm{U} / \mathrm{kg}$, Novolin) by IP injection. The blood glucose concentration was monitored before and after 15, 30, 60, and 120 min after injection. During GTT and ITT, mice were caged with blinded identity and random orders.

\section{Immunoblotting}

The expression and phosphorylation of each protein were analyzed by Western blot analysis. The membrane protein was extracted by using a membrane protein extraction kit (Merck Millipore). The protein was quantified using the Bradford reagent (BioRad). Before loading into the 10\% SDS-PAGE, the samples were mixed with a $5 x$ loading buffer and boiled at $98^{\circ} \mathrm{C}$ for $5 \mathrm{~min}$. After gel electrophoresis, the proteins 
were then transferred to a PVDF membrane $(0.45 \mu \mathrm{m}$, Merck Millipore) under $250 \mathrm{~mA}$ for $90 \mathrm{~min}$. The membranes were incubated with a blocking buffer (5\% non-fat milk in Trisbuffered saline containing $0.5 \%$ Tween-20) for $1 \mathrm{~h}$ at room temperature and then incubated with the indicated primary antibodies at $4^{\circ} \mathrm{C}$ overnight. The membrane was incubated with horseradish peroxidase-conjugated secondary antibody for $1 \mathrm{~h}$ at room temperature. The target protein bands were visualized using Amersham Imager 600 (GE healthcare).

Rabbit polyclonal to GLUT4(ab654,1:2,000), Rabbit polyclonal to PIP5K1A(ab654,1:1,000), and Mouse monoclonal to alpha 1 Sodium Potassium ATPase(ab7671, $5 \mu \mathrm{g} / \mathrm{ml})$ were purchased from Abcam (United Kingdom); Mouse Monoclonal Antibody to $\beta$-tubulin(TDY041, 1:1,000), Mouse Monoclonal Antibody to $\beta$ actin(TDY045, 1:1,000), Goat Polyclonal Antibody to Mouse IgG $(\mathrm{H}+\mathrm{L})$, HRP Conjugated(S001, 1:1,000), and Goat Polyclonal Antibody to Rabbit IgG (H + L), HRP Conjugated(S004, 1:1,000) were from TDY(Beijing, China).

\section{Dot-Blot Analysis}

$\mathrm{PI}(4,5) \mathrm{P}_{2}$ were measured by dot-blot analysis. C2C12 myotubes were treated with CFTR (inh)-172(Chemegen) for $24 \mathrm{~h}$. FDB muscle fibers isolated from CFTR KO, HET, WT mice. The whole-cell lysates were then extracted from $\mathrm{C} 2 \mathrm{C} 12$ myotubes, and FDB muscle fibers were blotted onto nitrocellulose membranes (Bio-Rad Laboratories). These were probed with $\mathrm{PI}(4,5) \mathrm{P}_{2}$ antibody (Abcam, \# ab11039) at a 1:500 dilution and detected using a horseradish peroxidase-conjugated secondary antibody (Beijing TDY Biotech LTD, \#E009) and were visualized using Amersham Imager 600 (GE healthcare). Experiments were repeated at least three times.

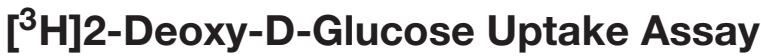

Uptake of $\left[{ }^{3} \mathrm{H}\right] 2$-deoxyglucose (Sigma, 73698-45-0) was measured in $\mathrm{C} 2 \mathrm{C} 12$ myocytes differentiated in 24-well plates. After differentiation, cells were washed twice with DMEM (GIBCO \#11965) and incubated in the DMEM for $2 \mathrm{~h}$ at $37^{\circ} \mathrm{C}$. Cells were then washed twice in PBS and then incubated in KRBB (G-clone, RS1800) in the presence or absence of insulin for $30 \mathrm{~min}$ at $37^{\circ} \mathrm{C}$. CFTR (inh)- 172 was added $30 \mathrm{~min}$ before insulin. After insulin treatment, uptake of $10 \mu \mathrm{M}\left[{ }^{3} \mathrm{H}\right] 2$ deoxyglucose was measured for $15 \mathrm{~min}$ at $37^{\circ} \mathrm{C}$. Reactions were terminated by rapidly washing the cells twice with cold KRBB. Cells were then were lysed in $0.1 \mathrm{~N} \mathrm{NaOH}$ with SDS $0.1 \%$, and radioactivity was determined by liquid scintillation counting and normalized according to the total protein content. Non-specific uptake was determined in the presence of $20 \mu \mathrm{M}$ cytochalasin B.

The mice's skeletal muscle was quickly dissected after killing the mice. Before the experiment, mice have fasted for $12 \mathrm{~h}$. Do not disturb the mice and keep them in a resting state. The muscles were incubated in $\mathrm{KRBB}$ in the presence or absence of insulin for $30 \mathrm{~min}$ at $37^{\circ} \mathrm{C}$, uptake of $10 \mu \mathrm{M}\left[{ }^{3} \mathrm{H}\right] 2$-deoxyglucose was measured for $15 \mathrm{~min}$ at $37^{\circ} \mathrm{C}$, as described above.

\section{Statistical Analysis}

All statistical calculations were carried out using Graphpad Prism 6. Data are expressed as average \pm SEM of at least three independent experiments. The statistical significance was determined using a $t$-test when comparing two groups and ANOVA when comparing multiple groups. A value of $P<0.05$ was considered statistically significant.

\section{RESULTS}

\section{CFTR Dysfunction Affects Mice's Glucose Homeostasis and Body Weight}

To investigate the connection between CFTR and glucose homeostasis, we performed insulin tolerance tests and glucose tolerance tests in 20-weeks-old male WT, heterozygous(HET), and CFTR KO mice (Figures 1A,B). During intraperitoneal insulin tolerance tests, the decrease in blood glucose was less marked in $\mathrm{CFTR}^{-/-}$mice than that of WT and HET mice following $10 \mathrm{mg} / \mathrm{ml}$ insulin injection (Figure 1A), suggesting insulin resistance. Moreover, the blood glucose level in $\mathrm{CFTR}^{-/-}$ mice was also much higher than that of WT and HET mice $2 \mathrm{~h}$ after insulin injection (Figure 1A). It took $\mathrm{CFTR}^{-/-}$ mice $60 \mathrm{~min}$ to reach the blood glucose summit in response to glucose tolerance tests, while it only took $15 \mathrm{~min}$ in WT and HET mice(Figure 1B). However, the glucose AUC was similar among WT and KO groups but slightly lower in the HE group (Figure 1C), indicating that the delay in attaining peak glucose levels during the OGTT suggests delayed glucose absorption. Reduced first, second, and amplifying phase secretion in CF islets have been reported by numerous researchers (Sun et al., 2017; Kelly et al., 2019); however, it was found that serum insulin level of $\mathrm{CFTR}^{-/-}$mice showed no significant difference than WT and HET mice by ELISA (Figure 1D), indicating that the amount of insulin secretion by $\mathrm{CFTR}^{-/-}$ mice was normal before CFRD. Notably, maintained in a stable environment with standard chow and water, CFTR ${ }^{-/-}$ mice's average body weight was much lower than WT and HET mice (Figure 1E). We suspected that the lower body weight of $\mathrm{CFTR}^{-/-}$mice resulted from inadequate glucose intake, but other possibilities include CFTR-related glucosuria or increased metabolic rate, requiring further confirmation. In conclusion, CFTR dysfunction affects mice's glucose homeostasis and body weight.

\section{CFTR Is Essential to Insulin-Induced GLUT4 Cell Membrane Translocation and Glucose Uptake}

When GLUT4 glucose transporters are present in cytoplasmic vesicles, they are useless for transporting glucose. The binding of insulin to receptors on such cells leads rapidly to the fusion of those vesicles with the plasma membrane and the insertion of the glucose transporters, thereby giving the cell the ability to take up glucose efficiently. As a result, glucose uptake depends on insulin-stimulated membrane translocation of the GLUT4. To investigate the relation between CFTR and GLUT4, GLUT4 cell membrane expression was measured by western blot in mice skeletal muscle fibers and $\mathrm{C} 2 \mathrm{C} 12$ myotubes. The Flexor Digitorum Brevis (FDB) muscle fibers 

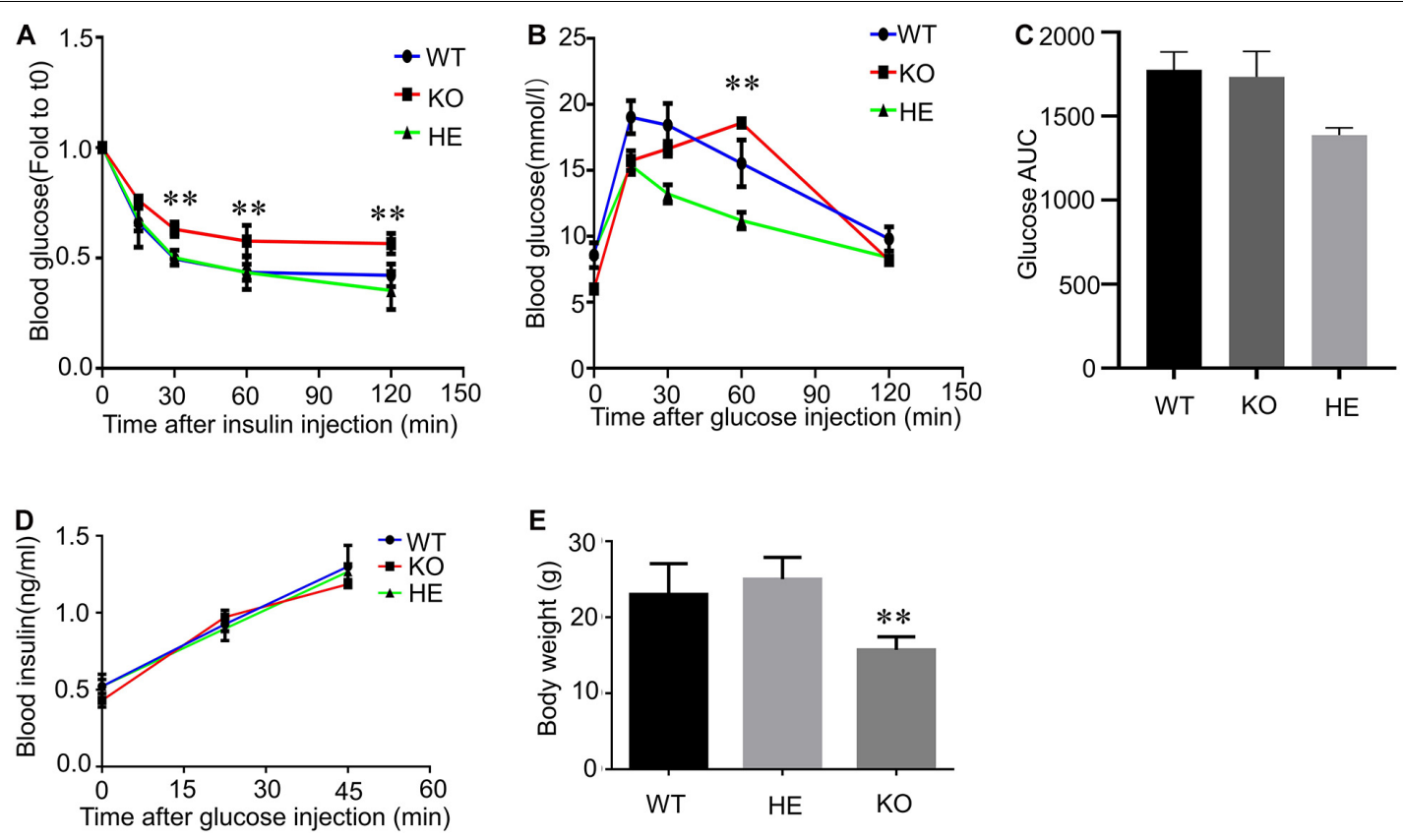

FIGURE 1 | Insulin resistance and Glucose tolerance in CFTR knockout mice. (A) Intraperitoneal insulin tolerance tests were performed in 20-weeks-old male mice WT, HET, and CFTR KO mice. ${ }^{\star \star} P<0.01$; NS, not significant. (B) OGTTs were performed in 20-weeks-old male mice WT, HET, and CFTR KO mice. ${ }^{\star \star} P$ < 0.01; NS, not significant. (C) Area under the curve (AUC) of changes in blood glucose levels. (D) Following an injection of $250 \mathrm{mg} / \mathrm{ml}$ glucose, serum insulin concentration was measured by ELISA. NS, not significant. (E) Bodyweight was measured in 20-weeks-old male mice WT, HET, and KO mice. Data are mean \pm SEM of 7-9 mice per group. ${ }^{\star \star} P<0.01$ vs. WT.

total membrane protein were immediately isolated from WT, HET, and CFTR KO mice $30 \mathrm{~min}$ after insulin injection stimulation. Evident membrane translocation of GLUT4 was found in WT and HET mice muscle fibers with insulin stimulation (Figure 2A). However, there was no membrane expression of GLUT4 in $\mathrm{CFTR}^{-/-}$mice with or without insulin stimulation (Figure 2A). Consistent with this, the insulin-stimulated GLUT4 cell surface translocation was also blocked by a specific CFTR inhibitor [CFTR (inh)-172] in differentiated C2C12 myotubes (Figure 2B). To directly show the translocation of GLUT4, C2C12 myoblasts and myotubes were transiently transfected with myc-GLUT4-EGFP fusion plasmids. Myc epitope was inserted in the first exofacial loop of GLUT4 $\mathrm{N}$ terminus and presented outside of the cell membrane, which could be detected by the antibody without perforation. C2C12 Cells were then fixed (without perforation) and labeled with an anti-Myc antibody followed by Texas Red secondary to track the membrane translocation of GLUT4 (red). We found that GLUT4 was expressed in the cytoplasm (Figures 2C,D, Control), and insulin could induce translocation of GLUT4 to cell membranes both in C2C12 myoblasts and myotubes (Figures 2C,D). However, this process could be blocked by CFTR (inh)-172 (Figures 2C,D). The effects of CFTR (inh)-172 on insulin-stimulated glucose uptake activity were also tested in differentiated $\mathrm{C} 2 \mathrm{C} 12$ myotubes and freshly isolated Flexor Digitorum Brevis (FDB) muscle fibers cells. We found that CFTR (inh)-172 significantly decreased 2-DG uptake in insulin-stimulated $\mathrm{C} 2 \mathrm{C} 12$ myotubes (Figure 2E) and freshly isolated Flexor Digitorum Brevis (FDB) muscle fibers cells (Figure 2F).

Some tissues, such as the liver, do not require insulin for efficient uptake of glucose; this is because these cells do not use GLUT4 to import glucose, but rather, GLUT1 and GLUT2 are not insulin-dependent. We wondered if similar results could be observed in liver cells. HEPG2 cells were transiently transfected with myc-GLUT4-EGFP fusion plasmids. HEPG2 Cells were then fixed (without perforation) and labeled with an anti-Myc antibody followed by Texas Red secondary to track the membrane translocation of GLUT4 (red). It was found that CFTR (inh)-172 could also block insulin-induced GLUT4 membrane translocation in HEPG2 (Supplementary Figure S1A) and Hela cells (Supplementary Figure S1B). To further confirm CFTR's role on GLUT4 translocation, as Hela cells endogenously express CFTR (Billet et al., 2017), we knocked out CFTR in Hela cells by CRISPR/Case9 (Supplementary Figure S1C). It was found that insulin could no longer induce GLUT4 translocation to the cell membrane in CFTR $^{-/-}$cells (Supplementary Figure S1D). Taken together, these results suggested that CFTR was required in insulin-induced membrane translocation of GLUT4.

\section{PI $(4,5) \mathrm{P}_{2}$ Rescues CFTR Related Defective GLUT4 Translocation}

Several studies indicated that Rab8A and Rab13 could also contribute to the translocation of GLUT4 (Sano et al., 2007; 

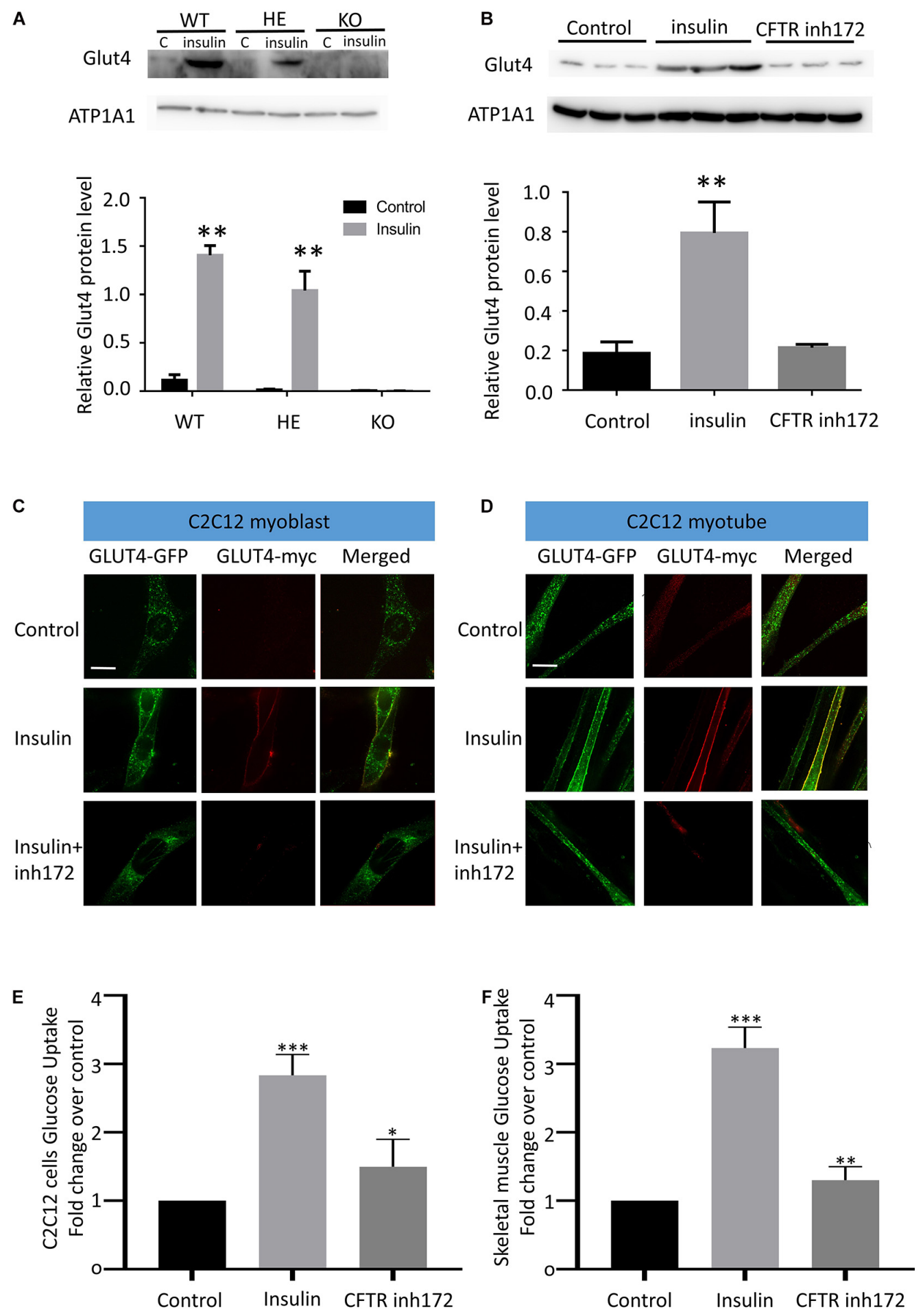

FIGURE 2 | CFTR regulates GLUT4 membrane translocation and glucose homeostasis. (A) The membrane localization of GLUT4 in CFTR KO mice FDB muscle after injection of $10 \mathrm{mg} / \mathrm{ml}$ insulin was measured by Western blot. Images are representative of triplicate experiments with similar results. ${ }^{* *} P<0.01$ compared with control $(n=3)$. (B) The membrane expression of GLUT4 in C2C12 myotubes was measured by Western blot. ${ }^{\star \star} P<0.01$ compared with control $(n=3)$.

(C) myc-GLUT4- GFP was transfected into C2C12 myoblasts by adenoviruses. The cells were stimulated with insulin (100 nM) for 30 min. GLUT4 translocation to the plasma membrane was detected by confocal microscopy. Glut4-GFP(green), Glut4-myc(red). Scale bar, $10 \mu \mathrm{m}$. (D) GLUT4 translocation to the plasma membrane of differentiated C2C12 myotubes was detected by confocal microscopy. Glut4-GFP(green), Glut4-myc(red). Scale bar, $10 \mu \mathrm{m}$. (E) The glucose uptake assay of $\mathrm{C} 2 \mathrm{C} 12$ cells. Data are mean $\pm \mathrm{SD}$ values for two independent assays performed in triplicate. ${ }^{\star \star \star} P<0.001,{ }^{\star} P<0.05$. (F) The glucose uptake assay of Flexor Digitorum Brevis muscle fibers cells. Data are mean $\pm \mathrm{SD}$ values for two independent assays performed in triplicate. ${ }^{\star \star \star} P<0.001,{ }^{\star \star} P<0.01$. 
Randhawa et al., 2008; Sun et al., 2010). Rab8A or Rab13 was co-transfected with myc-GLUT4-EGFP in Hela cells; we found that Rab8A or Rab13 could not rescue GLUT4 membrane translocation under CFTR (inh)-172 treatment (Figure 3A), suggesting Rab8A or Rab13 is not involved in this process. $\mathrm{PI}(4,5) \mathrm{P}_{2}$ mediated insulin-induced actin remodeling is another crucial component in GLUT4 translocation (Kanzaki and Pessin, 2001; Kanzaki et al., 2004; Leto and Saltiel, 2012; Lim et al., 2015). To identify the role of $\mathrm{PI}(4,5) \mathrm{P}_{2}$ in the process of GLUT4 translocation, C2C12 myotubes were transiently transfected with myc-GLUT4-EGFP fusion plasmids. Insulin-induced GLUT4 translocation in $\mathrm{C} 2 \mathrm{C} 12$ myotubes was blocked after endogenous $\mathrm{PI}(4,5) \mathrm{P}_{2}$ was depleted by application of both $\mathrm{PI}_{3} \mathrm{~K}$ inhibitor (wortmanin) and PLC agonist (Figure 3B). The defective GLUT4 membrane translocation induced by CFTR (inh)-172 could also be rescued by exogenous $\mathrm{PI}(4,5) \mathrm{P}_{2}$ (Figure 3B). As CFTR is a chloride channel, we suspected whether the chloride channel property of CFTR was also involved with GLUT4 translocation. By replacing the chloride with arginine in bath solution, we found that the translocation of GLUT4 was still blocked by CFTR (inh)172 (Supplementary Figure S2A). In conclusion, these results indicated that CFTR regulated GLUT4 membrane translocation by $\mathrm{PI}(4,5) \mathrm{P}_{2}$.

\section{CFTR Affects $\mathrm{PI}(4,5) \mathrm{P}_{2}$ Concentration via PIP5K1A}

To confirm the speculation that inhibition of CFTR might affect cellular $\mathrm{PI}(4,5) \mathrm{P}_{2}$ concentration. $\mathrm{PI}(4,5) \mathrm{P}_{2}$ concentration was detected by dot-blot analysis. C2C12 myotubes were treated with CFTR (inh)-172 for $24 \mathrm{~h}$, and we found that CFTR (inh)172 could significantly down-regulate $\mathrm{PI}(4,5) \mathrm{P}_{2}$ concentration (Figure 4A). We also measured the concentration of $\mathrm{PI}(4,5) \mathrm{P}_{2}$ in FDB muscle fibers isolated from CFTR WT, HET, and $\mathrm{KO}$ mice. The concentration of $\mathrm{PI}(4,5) \mathrm{P}_{2}$ in $\mathrm{CFTR}^{-/-}$mice FDB muscle fibers was significantly lower than WT and HET mice (Figure 4B). PIP5K1A induces the phosphorylation of phosphatidylinositol 4-phosphate (PtdIns4P) to generation $\mathrm{PI}(4,5) \mathrm{P}_{2}$. Studies indicated that that $\mathrm{PI}(4,5) \mathrm{P}_{2}$ generation by PIP5K1A was associated with GLUT4 vesicle recycling (Kanzaki et al., 2004) and autophagic lysosome reformation (Rong et al., 2012). To understand how CFTR regulates $\mathrm{PI}(4,5) \mathrm{P}_{2}$ expression, the PIP5K1A expression level was measured. We found that CFTR (inh)-172 induced a reduction of PIP5K1A expression in $\mathrm{C} 2 \mathrm{C} 12$ myotubes (Figure 4C). The expression of PIP5K1A was also significantly decreased in $\mathrm{CFTR}^{-/-}$FDB muscle fibers (Figure 4D). These results suggest that the effect of CFTR on $\mathrm{PI}(4,5) \mathrm{P}_{2}$ concentration is via the regulation of PIP5K1A expression.

\section{DISCUSSION}

In this study, we discovered a previously unrecognized regulation effect of CFTR to the GLUT4 cellular translocation, which provides a new perspective on the mechanism of CFRD. It was found that $\mathrm{CFTR}^{-/-}$mice exhibited normal insulin secretion but reduced insulin sensitivity and glucose tolerance. Insulin facilitates the entry of glucose into muscle through GLUT4. Meanwhile, Insulin-induced GLUT4 translocation to the cell membrane was also blocked in $\mathrm{CFTR}^{-/-}$mice, suggesting glucose homeostasis alteration from defective intracellular GLUT4 transportation. Unexpectedly, $\mathrm{PI}(4,5) \mathrm{P}_{2}$ could rescue the effect of CFTR deficiency. Furthermore, it was found that CFTR deficiency leads to a significantly decreased expression of PIP5K1A, which reflected on $\mathrm{PI}(4,5) \mathrm{P}_{2}$ concentration. Taken together, we discovered a new signal pathway of CFTR/GLUT4, which helps explain the glucose homeostasis disorder in CF patients.

To explain CFRD, several studies have shown that CFTR played a vital role in the regulation of insulin secretion and $\beta$ cell function (Tofe et al., 2005; Noronha et al., 2011; Konrad et al., 2013; Edlund et al., 2014; Guo et al., 2014). Some studies suggested that insulin resistance was not an essential determinant in CFRD compared with insulin secretion (Cucinotta et al., 1994; Yung et al., 2002). Other studies proved that insulin resistance was highly involved in CFRD, and impaired insulin responses were also reported in CF patients (Hardin et al., 1997; Hardin et al., 2001; Fontes et al., 2015). Our data show that insulin secretion is normal in $\mathrm{CFTR}^{-/-}$mice (Figure 1C); the problem is insulin sensitivity (Figure 1A) and glucose absorption (Figure 1B). Consistent with previous studies (Paroni et al., 2013; Fontes et al., 2015), we also found that the body weight was lower in $\mathrm{CFTR}^{-/-}$mice than WT and HET controls (Figure 1D). Gradual pancreatic destruction in cystic fibrosis causes progressive insulin deficiency. Our results show that in the early stage of CFRD, insulin secretion is expected, so insulin deficiency may not be due to the destruction of pancreatic islets, leading to insufficient insulin secretion, but because CFTR dysfunction affects the insulin-responsive tissues, which manifests as insulin deficiency. In summary, we believe that CFTR affects the pancreas functionality and the insulinresponsive tissues; both contribute to cystic fibrosis-related diabetes (CFRD).

How does CFTR knock out affected insulin sensitivity and glucose tolerance? By binding and activating its cell-surface receptor, insulin triggers signaling cascades that regulate many cellular processes, including stimulating the muscle to dispose of dietary glucose (Richter and Hargreaves, 2013). Insulin stimulation of glucose uptake into muscle depends on the mobilization of GLUT4 to the plasma membrane (Lauritzen et al., 2010; Klip et al., 2014). As Akt2 is an essential kinase in insulin resistance (Cho et al., 2001; McCurdy and Cartee, 2005), we investigate the phosphorylation of Akt2 in CFTR ${ }^{-/-}$ mice. Surprisingly, CFTR deficiency showed no connection with phosphorylation of Akt2 and its downstream protein AS160 (data not shown). Furthermore, other regulators, such as Rab8A and Rab13, also showed no significant impact on CFTR deficiencyinduced GLUT4 translocation (Figure 3A). As a result, we focused on the "railway" of protein trafficking in the cell, and studies showed that actin remodeling also played an essential regulatory role in insulin-induced GLUT4 translocation (Kanzaki and Pessin, 2001; Tong et al., 2001). The role of actin dynamic 


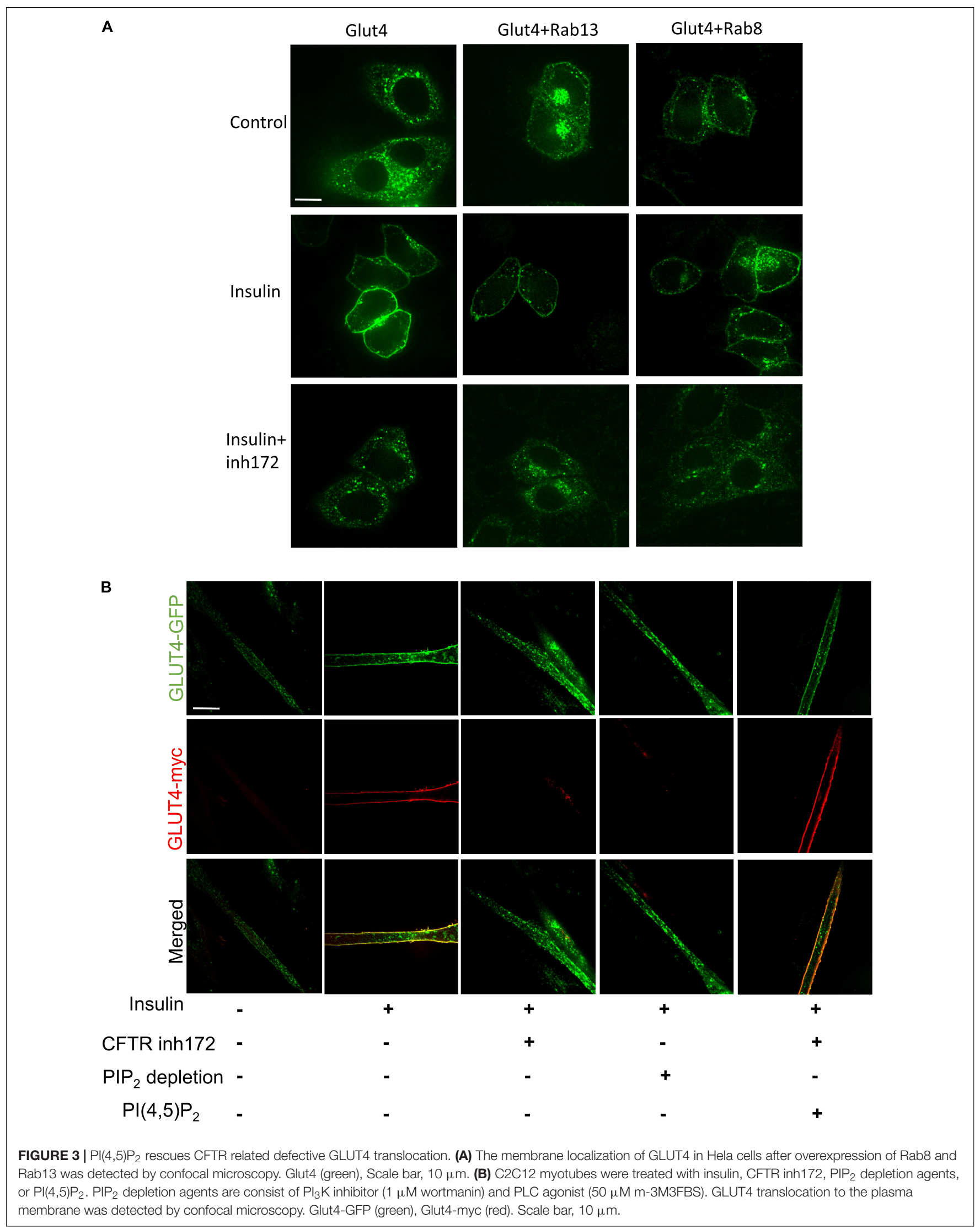



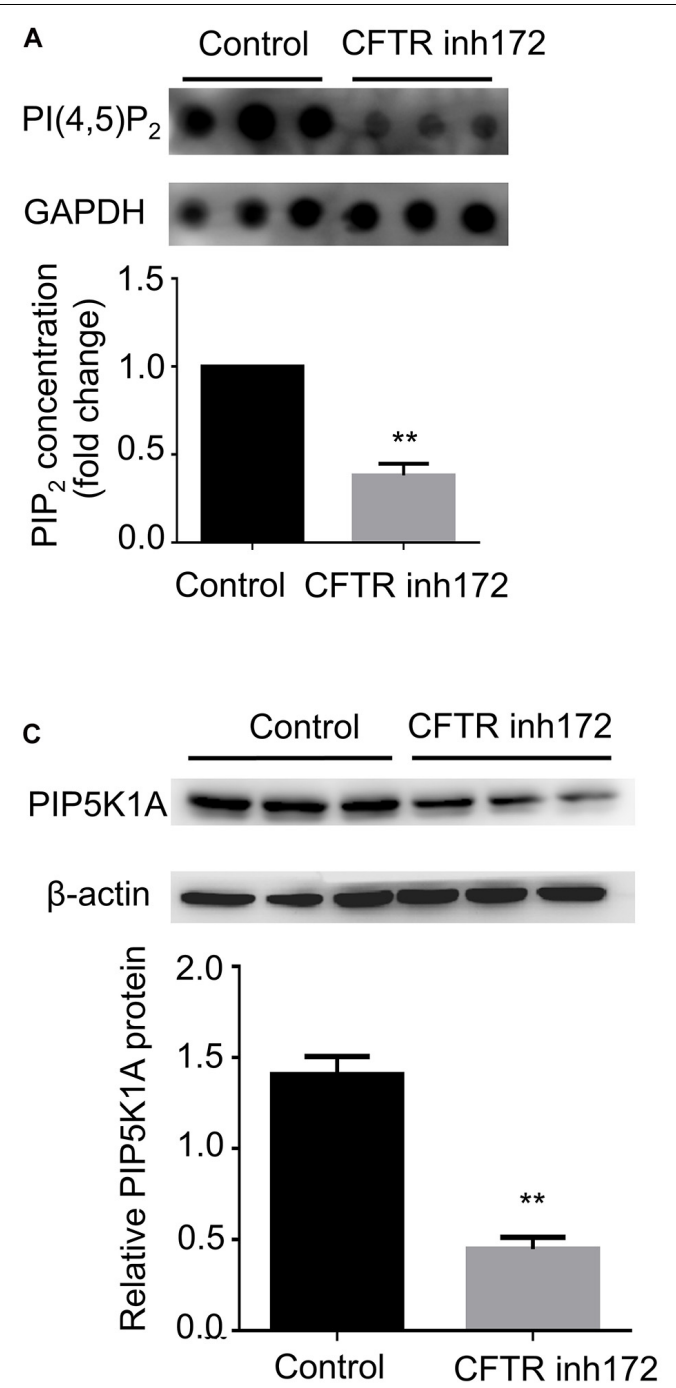
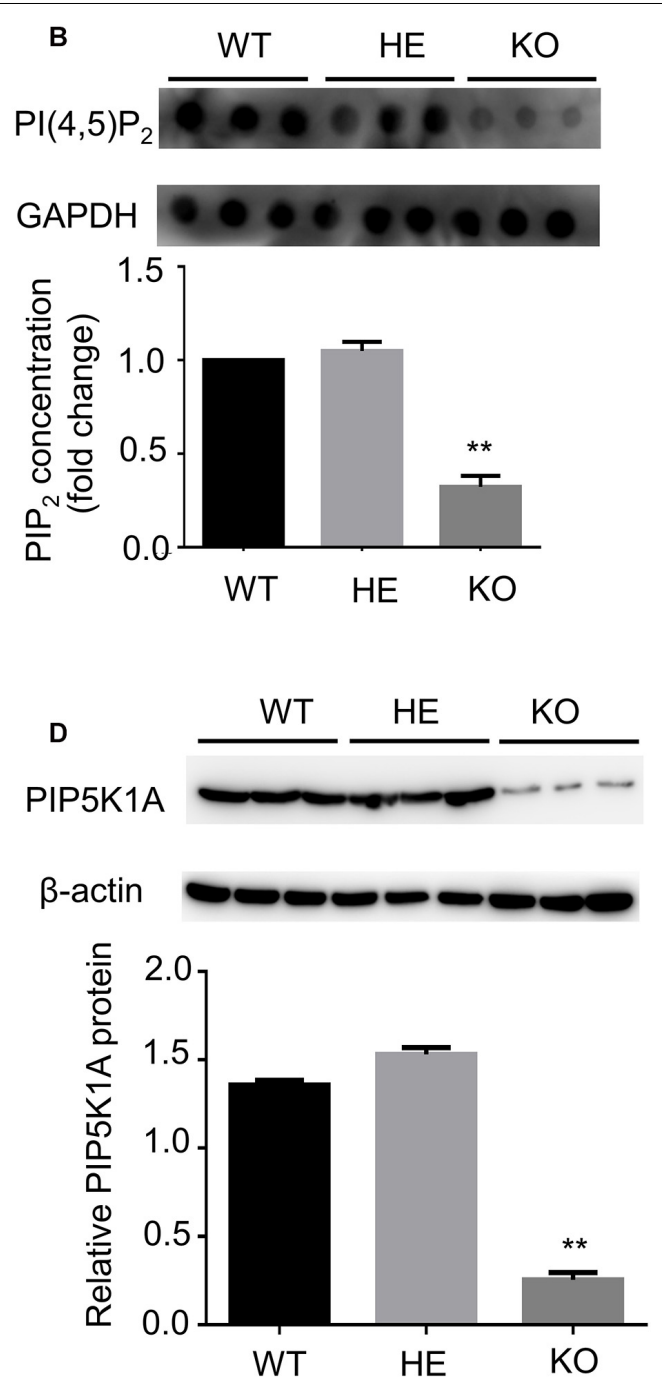

FIGURE 4 | CFTR regulates PIP5KA expression and PI(4,5) $\mathrm{P}_{2}$ concentration. (A) C2C12 myotubes were treated with CFTR inh172, and the concentration of $\mathrm{PI}(4,5) \mathrm{P}_{2}$ was measured by dot blot. ${ }^{\star *} \mathrm{P}<0.01$ compared with control $(n=3)$. (B) The concentration of $\mathrm{PI}(4,5) \mathrm{P}_{2}$ in mice FDB muscle was measured by dot blot. ${ }^{* *} P<0.01$ compared with control $(n=3)$. (C) C2C12 myotubes were treated with CFTR inh172, and the protein level of PIP5KA was measured by western blot. ${ }^{\star \star} P<0.01$ compared with control $(n=3)$. (D) The protein level of PIP5KA in mice FDB muscle was measured by western blot. ${ }^{\star \star} P<0.01$ compared with control $(n=3)$.

regulated by $\mathrm{PI}(4,5) \mathrm{P}_{2}$ in GLUT4 translocation has been proved by recent studies (Kanzaki and Pessin, 2001; Kanzaki et al., 2004; Leto and Saltiel, 2012; Lim et al., 2015). Our data show that the depletion of $\mathrm{PI}(4,5) \mathrm{P}_{2}$ blocks GLUT4 trafficking to the cell membrane, and exogenous $\mathrm{PI}(4,5) \mathrm{P}_{2}$ can rescue the effect of CFTR deficiency. Thus, we conclude that CFTR in GLUT4 translocation regulation is mediated by $\mathrm{PI}(4,5) \mathrm{P}_{2}$. In addition to insulin-stimulation, the translocation of GLUT4 to the plasma membrane is also affected by skeletal muscle contraction. Whether CFTR has a role in skeletal muscle contraction needs further clarification.

As CFTR is an ion channel, which makes no sense in catalyzing $\mathrm{PI}(4,5) \mathrm{P}_{2}$ generation. We proved that the chloride channel property of CFTR was not involved with GLUT4 translocation; only the protein itself is involved in translocation. Therefore, we speculated that CFTR allosteric affects some kinase proteins in the regulation of $\mathrm{PI}(4,5) \mathrm{P} 2$ generation. The differential gene expression induced by CFTR deficiency has been reported by several studies (Ichikawa et al., 2000; Ogilvie et al., 2011; Chen et al., 2012). We suspected that inhibition or knockdown of CFTR might lead to decreased PIP5K1A expression, which regulates $\mathrm{PI}(4,5) \mathrm{P}_{2}$ generation. We found that the expression of PIP5K1A in $\mathrm{CFTR}^{-/-}$mice and CFTR (inh)-172 treated C2C12 was significantly reduced, causing lower $\mathrm{PI}(4,5) \mathrm{P}_{2}$ concentration. In conclusion, PIP5K1A is one of the regulators between CFTR and $\mathrm{PI}(4,5) \mathrm{P}_{2}$, but further investigation is needed to assess how CFTR deficiency regulates PIP5K1A expression.

In summary, our results suggest a new mechanism of glucose homeostasis disorder in CF patients. These findings identify the role of GLUT4 translocation in CFTR related glucose 
homeostasis disorder in CF patients, which provides a new potential treatment strategy.

\section{DATA AVAILABILITY STATEMENT}

The original contributions presented in the study are included in the article/Supplementary Material, further inquiries can be directed to the corresponding author/s.

\section{ETHICS STATEMENT}

The animal study was reviewed and approved by the University Ethics Committee, Institute of Molecular Medicine, Peking University.

\section{AUTHOR CONTRIBUTIONS}

YG and LW conceived and coordinated the study. JG and LW conducted molecular experiments and wrote the manuscript. WZ and JG performed the imaging-related experiments. All authors

\section{REFERENCES}

Billet, A., Froux, L., Hanrahan, J. W., and Becq, F. (2017). Development of automated patch clamp technique to investigate $\mathrm{cttr}$ chloride channel function. Front. Pharmacol. 8:195. doi: 10.3389/fphar.2017.00195

Bouche, C., Serdy, S., Kahn, C. R., and Goldfine, A. B. (2004). The cellular fate of glucose and its relevance in type 2 diabetes. Endocr. Rev. 25, 807-830. doi: 10.1210/er.2003-0026

Boudreau, V., Coriati, A., Hammana, I., Ziai, S., Desjardins, K., Berthiaume, Y., et al. (2016). Variation of glucose tolerance in adult patients with cystic fibrosis: what is the potential contribution of insulin sensitivity? J. Cystic Fibr. 15, 839-845. doi: 10.1016/j.jcf.2016.04.004

Chen, J., Fok, K. L., Chen, H., Zhang, X. H., Xu, W. M., and Chan, H. C. (2012). Cryptorchidism-induced CFTR down-regulation results in disruption of testicular tight junctions through up-regulation of NF-kappaB/COX2/PGE2. Hum. Reprod. 27, 2585-2597. doi: 10.1093/humrep/des254

Cho, H., Mu, J., Kim, J. K., Thorvaldsen, J. L., Chu, Q., Crenshaw, E. B. III, et al. (2001). Insulin resistance and a diabetes mellitus-like syndrome in mice lacking the protein kinase Akt2 (PKB beta). Science 292, 1728-1731. doi: 10.1126/ science.292.5522.1728

Costa, M., Potvin, S., Hammana, I., Malet, A., Berthiaume, Y., Jeanneret, A., et al. (2007). Increased glucose excursion in cystic fibrosis and its association with a worse clinical status. J. Cystic Fibr. 6, 376-383. doi: 10.1016/j.jcf.2007.02.005

Cucinotta, D., De Luca, F., Gigante, A., Arrigo, T., Di Benedetto, A., Tedeschi, A., et al. (1994). No changes of insulin sensitivity in cystic fibrosis patients with different degrees of glucose tolerance: an epidemiological and longitudinal study. Eur. J Endocrinol. 130, 253-258. doi: 10.1530/eje.0.1300253

Edlund, A., Esguerra, J. L., Wendt, A., Flodstrom-Tullberg, M., and Eliasson, L. (2014). CFTR and Anoctamin 1 (ANO1) contribute to cAMP amplified exocytosis and insulin secretion in human and murine pancreatic beta-cells. BMC Med. 12:87. doi: 10.1186/1741-7015-12-87

Fontes, G., Ghislain, J., Benterki, I., Zarrouki, B., Trudel, D., Berthiaume, Y., et al. (2015). The DeltaF508 mutation in the cystic fibrosis transmembrane conductance regulator is associated with progressive insulin resistance and decreased functional beta-cell mass in mice. Diabetes 64, 4112-4122. doi: $10.2337 / \mathrm{db} 14-0810$

Guo, J. H., Chen, H., Ruan, Y. C., Zhang, X. L., Zhang, X. H., Fok, K. L., et al. (2014). Glucose-induced electrical activities and insulin secretion in pancreatic islet beta-cells are modulated by CFTR. Nat. Commun. 5:4420. made critical contributions to data analysis, interpretation, discussion, and manuscript preparation and approved the final version.

\section{FUNDING}

This work was supported by the National Basic Research Program of China (973 Program) (2013CB531206 and 2012CB517803) and the National Natural Science Foundation of China (81170236 and 31127001).

\section{SUPPLEMENTARY MATERIAL}

The Supplementary Material for this article can be found online at: https://www.frontiersin.org/articles/10.3389/fcell.2021. 630654/full\#supplementary-material

Supplementary Figure 1 | Insulin-induced GLUT4 translocation in HEPG2 and Hela cells.

Supplementary Figure 2 | Chloride channel property of CFTR and insulin-induced GLUT4 translocation.

Hardin, D. S., LeBlanc, A., Lukenbough, S., and Seilheimer, D. K. (1997). Insulin resistance is associated with decreased clinical status in cystic fibrosis. J. Pediatr. 130, 948-956. doi: 10.1016/s0022-3476(97)70282-8

Hardin, D. S., Leblanc, A., Marshall, G., and Seilheimer, D. K. (2001). Mechanisms of insulin resistance in cystic fibrosis. Am. J. Physiol. Endocrinol. Metab. 281, E1022-E1028.

Holl, R. W., Heinze, E., Wolf, A., Rank, M., and Teller, W. M. (1995). Reduced pancreatic insulin release and reduced peripheral insulin sensitivity contribute to hyperglycaemia in cystic fibrosis. Eur. J. Pediatr. 154, 356-361. doi: 10.1007/ s004310050303

Iannucci, A., Mukai, K., Johnson, D., and Burke, B. (1984). Endocrine pancreas in cystic fibrosis: an immunohistochemical study. Hum. Pathol. 15, 278-284. doi: 10.1016/s0046-8177(84)80191-4

Ichikawa, J. K., Norris, A., Bangera, M. G., Geiss, G. K., van 't Wout, A. B., Bumgarner, R. E., et al. (2000). Interaction of Pseudomonas aeruginosa with epithelial cells: identification of differentially regulated genes by expression microarray analysis of human cDNAs. Proc. Natl. Acad. Sci. U.S.A. 97, 96599664. doi: 10.1073/pnas.160140297

Kanzaki, M., Furukawa, M., Raab, W., and Pessin, J. E. (2004). Phosphatidylinositol 4,5-bisphosphate regulates adipocyte actin dynamics and GLUT4 vesicle recycling. J. Biol. Chem. 279, 30622-30633. doi: 10.1074/jbc.m401443200

Kanzaki, M., and Pessin, J. E. (2001). Insulin-stimulated GLUT4 translocation in adipocytes is dependent upon cortical actin remodeling. J. Biol. Chem. 276, 42436-42444. doi: 10.1074/jbc.m108297200

Kelly, A., De Leon, D. D., Sheikh, S., Camburn, D., Kubrak, C., Peleckis, A. J., et al. (2019). Islet hormone and incretin secretion in cystic fibrosis after four months of ivacaftor therapy. Am. J. Respir. Crit. Care Med. 199, 342-351. doi: 10.1164/rccm.201806-1018oc

Klip, A., Sun, Y., Chiu, T. T., and Foley, K. P. (2014). Signal transduction meets vesicle traffic: the software and hardware of GLUT4 translocation. Am. J. Physiol. Cell Physiol. 306, C879-C886.

Konrad, K., Scheuing, N., Badenhoop, K., Borkenstein, M. H., Gohlke, B., Schofl, C., et al. (2013). Cystic fibrosis-related diabetes compared with type 1 and type 2 diabetes in adults. Diabetes 29, 568-575.

Lauritzen, H. P., Galbo, H., Toyoda, T., and Goodyear, L. J. (2010). Kinetics of contraction-induced GLUT4 translocation in skeletal muscle fibers from living mice. Diabetes 59, 2134-2144. doi: $10.2337 / \mathrm{db} 10-0233$

Leto, D., and Saltiel, A. R. (2012). Regulation of glucose transport by insulin: traffic control of GLUT4. Nat. Rev. Mol. Cell Biol. 13, 383-396. doi: 10.1038/nrm3351 
Lim, C. Y., Bi, X., Wu, D., Kim, J. B., Gunning, P. W., Hong, W., et al. (2015). Tropomodulin3 is a novel Akt2 effector regulating insulin-stimulated GLUT4 exocytosis through cortical actin remodeling. Nat. Commun. 6:5951.

Lohr, M., Goertchen, P., Nizze, H., Gould, N. S., Gould, V. E., Oberholzer, M., et al. (1989). Cystic fibrosis associated islet changes may provide a basis for diabetes. An immunocytochemical and morphometrical study. Virchows Arch. A Pathol. Anat. Histopathol. 414, 179-185. doi: 10.1007/bf00718598

Manderson Koivula, F. N., McClenaghan, N. H., Harper, A. G. S., and Kelly, C. (2017). Correction to: islet-intrinsic effects of CFTR mutation. Diabetologia 60, 2544. doi: 10.1007/s00125-017-4474-1

Marshall, B. C., Butler, S. M., Stoddard, M., Moran, A. M., Liou, T. G., and Morgan, W. J. (2005). Epidemiology of cystic fibrosis-related diabetes. J. Pediatr. 146, 681-687.

McCurdy, C. E., and Cartee, G. D. (2005). Akt2 is essential for the full effect of calorie restriction on insulin-stimulated glucose uptake in skeletal muscle. Diabetes 54, 1349-1356. doi: 10.2337/diabetes.54.5.1349

Mohan, K., Miller, H., Dyce, P., Grainger, R., Hughes, R., Vora, J., et al. (2009). Mechanisms of glucose intolerance in cystic fibrosis. Diabet. Med. 26, 582-588. doi: 10.1111/j.1464-5491.2009.02738.x

Moran, A., Becker, D., Casella, S. J., Gottlieb, P. A., Kirkman, M. S., Marshall, B. C., et al. (2010). Committee CFRD consensus conference committee. Epidemiology, pathophysiology, and prognostic implications of cystic fibrosisrelated diabetes: a technical review. Diabet. Care 33, 2677-2683. doi: 10.2337/ dc10- 1279

Moran, A., Dunitz, J., Nathan, B., Saeed, A., Holme, B., and Thomas, W. (2009). Cystic fibrosis-related diabetes: current trends in prevalence, incidence, and mortality. Diabet. Care 32, 1626-1631. doi: 10.2337/dc09-0586

Moran, A., Pyzdrowski, K. L., Weinreb, J., Kahn, B. B., Smith, S. A., Adams, K. S., et al. (1994). Insulin sensitivity in cystic fibrosis. Diabetes 43, 1020-1026.

Noronha, R. M., Calliari, L. E., Damaceno, N., Muramatu, L. H., and Monte, O. (2011). Update on diagnosis and monitoring of cystic fibrosis-related diabetes mellitus (CFRD). Arq. Bras. Endocrinol. Metabol. 55, 613-621. doi: 10.1590/ s0004-27302011000800016

Ogilvie, V., Passmore, M., Hyndman, L., Jones, L., Stevenson, B., Wilson, A., et al. (2011). Differential global gene expression in cystic fibrosis nasal and bronchial epithelium. Genomics 98, 327-336. doi: 10.1016/j.ygeno.2011.06.008

Park, K. H., Weisleder, N., Zhou, J., Gumpper, K., Zhou, X., Duann, P., et al. (2014). Assessment of calcium sparks in intact skeletal muscle fibers. J. Vis. Exp. 84:e50898.

Paroni, M., Moalli, F., Nebuloni, M., Pasqualini, F., Bonfield, T., Nonis, A., et al. (2013). Response of CFTR-deficient mice to long-term chronic Pseudomonas aeruginosa infection and PTX3 therapy. J. Infect. Dis. 208, 130-138. doi: 10. 1093/infdis/jis636

Randhawa, V. K., Ishikura, S., Talior-Volodarsky, I., Cheng, A. W., Patel, N., Hartwig, J. H., et al. (2008). GLUT4 vesicle recruitment and fusion are differentially regulated by Rac, AS160, and Rab8A in muscle cells. J. Biol. Chem. 283, 27208-27219. doi: 10.1074/jbc.m804282200
Richter, E. A., and Hargreaves, M. (2013). Exercise. GLUT4, and skeletal muscle glucose uptake. Physiol. Rev. 93, 993-1017. doi: 10.1152/physrev.00038.2012

Rong, Y., Liu, M., Ma, L., Du, W., Zhang, H., Tian, Y., et al. (2012). Clathrin and phosphatidylinositol-4,5-bisphosphate regulate autophagic lysosome reformation. Nat. Cell Biol. 14, 924-934. doi: 10.1038/ncb2557

Sano, H., Eguez, L., Teruel, M. N., Fukuda, M., Chuang, T. D., Chavez, J. A., et al. (2007). Rab10, a target of the AS160 Rab GAP, is required for insulin-stimulated translocation of GLUT4 to the adipocyte plasma membrane. Cell Metab. 5, 293-303. doi: 10.1016/j.cmet.2007.03.001

Stalvey, M. S., Muller, C., Schatz, D. A., Wasserfall, C. H., Campbell-Thompson, M. L., Theriaque, D. W., et al. (2006). Cystic fibrosis transmembrane conductance regulator deficiency exacerbates islet cell dysfunction after betacell injury. Diabetes 55, 1939-1945. doi: 10.2337/db05-1647

Sun, X., Yi, Y., Xie, W., Liang, B., Winter, M. C., He, N., et al. (2017). CFTR influences beta cell function and insulin secretion through non-cell autonomous exocrine-derived factors. Endocrinology 158, 3325-3338. doi: 10. 1210/en.2017-00187

Sun, Y., Bilan, P. J., Liu, Z., and Klip, A. (2010). Rab8A and Rab13 are activated by insulin and regulate GLUT4 translocation in muscle cells. Proc. Natl. Acad. Sci. U.S.A. 107, 19909-19914. doi: 10.1073/pnas.10095 23107

Tofe, S., Moreno, J. C., Maiz, L., Alonso, M., Escobar, H., and Barrio, R. (2005). Insulin-secretion abnormalities and clinical deterioration related to impaired glucose tolerance in cystic fibrosis. Eur. J. Endocrinol. 152, 241-247. doi: 10. 1530/eje.1.01836

Tong, P., Khayat, Z. A., Huang, C., Patel, N., Ueyama, A., and Klip, A. (2001). Insulin-induced cortical actin remodeling promotes GLUT4 insertion at muscle cell membrane ruffles. J. Clin. Invest. 108, 371-381. doi: 10.1172/jci2001 12348

Wooldridge, J. L., Szczesniak, R. D., Fenchel, M. C., and Elder, D. A. (2015). Insulin secretion abnormalities in exocrine pancreatic sufficient cystic fibrosis patients. J. Cystic Fibr. 14, 792-797. doi: 10.1016/j.jcf.2015.02.009

Yung, B., Noormohamed, F. H., Kemp, M., Hooper, J., Lant, A. F., and Hodson, M. E. (2002). Cystic fibrosis-related diabetes: the role of peripheral insulin resistance and beta-cell dysfunction. Diabet. Med. 19, 221-226. doi: 10.1046/ j.1464-5491.2002.00666.x

Conflict of Interest: The authors declare that the research was conducted in the absence of any commercial or financial relationships that could be construed as a potential conflict of interest.

Copyright (c) $2021 \mathrm{Gu}$, Zhang, Wu and Gu. This is an open-access article distributed under the terms of the Creative Commons Attribution License (CC BY). The use, distribution or reproduction in other forums is permitted, provided the original author(s) and the copyright owner(s) are credited and that the original publication in this journal is cited, in accordance with accepted academic practice. No use, distribution or reproduction is permitted which does not comply with these terms. 